\title{
ENTREVISTA
}

\section{Música, Masonería y Poder en la Venezuela del siglo XIX}

El investigador Juan de Dios López Maya ha defendido una Tesis Doctoral cuyo título es "Música, Masonería y Poder en la Venezuela del siglo XIX" en la Universidad Central de Venezuela en Caracas, el 21 de mayo de 2015. Juan de Dios López nació en 1962 en Venezuela.

El autor nos ha concedido la siguiente entrevista.

¿Cuáles fueron los motivos que le llevó a enfocar su investigación hacia la Masonería?

Mi principal motivación fue la de aportar algo novedoso a la musicología y a la historia de Venezuela al mismo tiempo. En mi carrera como musicólogo me he dedicado, casi exclusivamente, al rescate y edición de obras musicales venezolanas del siglo XIX. En el año 2009, revisando las colecciones de música de la Biblioteca Nacional de Venezuela, me topé con una partitura manuscrita que contenía música escrita específicamente para una ceremonia masónica. El autor de esta obra era Atanasio Bello Montero, uno de los principales compositores en la Caracas de mediados del siglo XIX. Una revisión más profunda de los archivos musicales de la Biblioteca, dio como resultado el hallazgo de once partituras que tenían el mismo destino que la obra de Bello Montero. Entre los autores figuraban algunos de los músicos más conocidos de la capital y también de la provincia. Entre ellos José Ángel Montero, reconocido, en aquel entonces y hoy en día, como el mejor y más fecundo compositor de todo el siglo XIX en nuestro país. Aunque estas partituras estaban en la Biblioteca desde hace muchos años, ningún investigador se había ocupado de ellas. En uno de los textos clásicos de la musicología venezolana, La Ciudad y su Música de José Antonio Calcaño (2001:169), apenas se menciona una vez la existencia de música masónica en el siglo XIX ${ }^{1}$.

Mi intención era realizar una edición crítica de esta música. Para este fin consideré necesario consultar la bibliografía existente sobre historia de la masonería en Venezuela. Al hacerlo me di cuenta que, salvo contadas excepciones, ésta no había sido tratada por historiadores profesionales, y casi todo lo que se había escrito era de carácter apologético. Decidí entonces, buscar fuentes primarias, pues ya el tema comenzaba a apasionarme y quería conseguir datos más confiables. Por fortuna, la Biblioteca Nacional cuenta con abundante material sobre la masonería: prensa masónica de finales del siglo XIX, libros

${ }^{1}$ J. Calcaño, La Ciudad y su Música (Caracas: Ediciones de la Biblioteca de la Universidad Central de Venezuela, 2001 [publicado por primera vez en 1958]). 
teóricos, folletos publicados por logias y, lo mejor de todo, el archivo de una conocida logia del siglo XIX, llamada Esperanza $n^{\circ} 7$.

La revisión de este material fue una sorpresa mayúscula para mí. Pues, además de los compositores de las once obras encontradas en la Biblioteca, descubrí que un gran número de reconocidos músicos de la época habían sido masones. Pero, aparte de lo puramente musical, los documentos contenían información que sugería que los masones, y la masonería como institución, habían estado involucrados en casi todas las actividades de la vida venezolana desde comienzos del siglo XIX. Esto se notaba especialmente en el ejercicio del poder político; todos los presidentes de la República en ese siglo eran masones del grado $33^{\circ}$. También eran masones muchos oficiales de las fuerzas armadas, ministros, gobernadores de provincias, jueces, comerciantes e intelectuales. Casi todas las logias se dedicaban a actividades filantrópicas; organizaban y patrocinaban conciertos y obras de teatro para recaudar fondos destinados a obras de caridad. Esto demostraba que la Masonería decimonónica venezolana tenía una relación abierta con la sociedad y, hasta este momento, muy pocos investigadores se han percatado de ello. Me decidí entonces a realizar un proyecto más ambicioso: una edición crítica de la música, acompañada de un ensayo sobre la relación entre ésta, la masonería y la sociedad de la época.

¿Cuáles fueron las fuentes que ha utilizado?

En el Archivo Audiovisual de la Biblioteca Nacional de Venezuela se encuentran las once partituras masónicas que mencioné anteriormente. En este fondo hay más de diez mil obras musicales manuscritas e impresas, abarcando un periodo que va desde finales del siglo XVIII hasta nuestros días.

En la Hemeroteca Nacional hay un total de once periódicos masónicos que circularon en Venezuela entre 1867 y 1901. Las noticias sobre eventos musicales, organizados o patrocinados por las distintas logias, constituyeron otra fuente importante para la investigación.

En la sección de Libros Raros de la Biblioteca Nacional se encuentra, como ya he dicho, el archivo de la logia Esperanza $n^{\circ}$; hay en él muchos documentos que contienen información sobre las actividades musicales de dicha logia. Esperanza $n^{\circ} 7$ fue fundada en Caracas en 1853 y era una de las logias más activas de la época; a ella pertenecieron, entre otros, Antonio Guzmán Blanco, tres veces presidente de la República.

La Academia Nacional de la Historia posee también una hemeroteca en donde se pueden consultar las mismas publicaciones periódicas existentes en la Hemeroteca Nacional, pero los ejemplares están en mejor estado de conservación. Además, la Academia posee un archivo masónico que perteneció a Arístides Rojas, un personaje de amplia trayectoria en la vida pública de ese entonces.

En cuanto a las instituciones masónicas propiamente dichas, hay que destacar que el 
Gran Templo Masónico de Caracas, sede de varias logias y otros cuerpos masónicos, posee una abundante documentación. El problema es que no existe ahí ningún criterio profesional de catalogación. Además, el estado de conservación de los documentos es malo y dificulta mucho su consulta.

Otras fuentes fueron ubicadas en dos logias de la provincia: Victoria $n^{\circ} 9 \mathrm{y}$ Unanimidad $n^{\circ} 3$. En la logia Victoria, fundada en 1854, hay un archivo bastante bien conservado y organizado. En la logia Unanimidad, fundada en 1822, y por lo tanto una de las más antiguas de Venezuela, se consiguieron cinco cuadernos con música manuscrita. Estos fueron presumiblemente usados por esta logia con fines rituales y también sociales; además de música litúrgica masónica, contienen piezas de baile, obras litúrgicas católicas, marchas y música sinfónica. Los cuadernos no poseen fecha y están muy deteriorados, pero todo indica que fueron escritos entre 1870 y 1900.

¿Cuáles fueron las principales dificultades con las que se ha encontrado? ¿Cómo las ha superado?

La principal dificultad fue entender como se había utilizado la música en el marco de las ceremonias. Esto fue resuelto consultando las liturgias, libros teóricos y descripciones de tenidas en los cuales se indicaba en que momento, de los diferentes ritos, había intervenciones musicales y como debía ser el carácter de la música

El mal estado de conservación de los cuadernos de música de la logia Unanimidad entorpeció mucho su transcripción. Este problema fue resuelto tomando fotografías de alta resolución de las partituras y luego amplificándolas en la pantalla del ordenador.

Otra dificultad surgió a la hora de interpretar el uso de la música en las tenidas blancas $^{2}$. Algo que se evidenciaba tanto en la prensa masónica como en la regular. ¿Había la Masonería utilizado la música como una herramienta política? En su obra Ruidos, el musicólogo Jacques Attali, afirma que la música es muchas veces un lazo de unión entre el poder y sus súbditos, y por lo tanto, generalmente, un atributo del poder ${ }^{3}$ (1995:16). Esta afirmación me permitió entender que la institución masónica, tratando de crear una imagen de respetabilidad y confiabilidad ante la sociedad, había utilizado la música como herramienta mediática. Al organizar conciertos públicos con fines benéficos, en donde se escuchaban fragmentos de óperas que estaban de moda, obras sinfónicas de conocidos compositores europeos, piezas de baile y hasta alguna obra litúrgica católica en latín, la institución enviaba un mensaje a las clases altas y medias de la sociedad. Expresándolo en primera persona, este mensaje sonaría más o menos así: los masones controlamos el poder, pero no teman; somos personas cultas, civilizadas, caritativas y además buenos cristianos

\footnotetext{
${ }^{2}$ Se llaman así las ceremonias masónicas abiertas a personas no iniciadas en la Orden.

${ }^{3}$ J. Attali, Ruidos, ensayo sobre la economía política de la música (México: Siglo XXI, 1995).
} 
aunque la Iglesia lo niegue. Merece destacarse que, en la relación entre la Iglesia y la Masonería en Venezuela, era la Iglesia quien generalmente llevaba la peor parte.

¿Cuáles fueron las principales problemáticas históricas que su trabajo ha resuelto?

Lo principal fue descubrir un repertorio musical que nadie conocía hasta el momento. En este sentido, muchos países europeos, y también los Estados Unidos, tienen publicaciones de música masónica de los siglos XVIII, XIX y XX, además de una bibliografía amplia y actualizada acerca del tema masónico musical. En Venezuela, y me atrevo a decir, en Latinoamérica y el Caribe, esto no sucede, a pesar de la importancia y la presencia que la Orden tuvo a lo largo del siglo XIX.

Por otra parte, al presentar a la masonería venezolana como un actor social, se destruye el mito de la sociedad secreta y clandestina, que todavía es un lugar común en los medios académicos venezolanos. Fue muy revelador leer en la prensa que el Presidente de la República, y varios miembros de su gabinete, se presentaron en una tenida blanca, luciendo con orgullo sus mandiles y dando golpes de mallete.

Finalmente, el trabajo es un aporte en relación con la ubicación y descripción de los fondos consultados. Muchas logias antiguas, que funcionan en la provincia, no pudieron ser visitadas, lo cual deja abierta la investigación.

¿Por favor, podría resumir la esencia de su Tesis en dos líneas?

La Masonería venezolana, estrechamente vinculada con el poder durante el siglo XIX, utilizó la música con dos propósitos: el primero, satisfacer una necesidad litúrgica; y el segundo, crear una imagen positiva de sí misma ante la sociedad.

¿Cuáles fueron las lecciones, a todos los niveles, personal y profesional, que usted ha deducido de su experiencia investigativa?

Lo más importante, a nivel personal, fue haber entrado en contacto con el mundo de la Masonería. La experiencia fue, y sigue siendo, enriquecedora, tanto en lo personal como en lo profesional. Algo fundamental que aprendí es que en Venezuela, no importa lo meticuloso que uno sea al realizar el arqueo de fuentes, siempre la casualidad interviene en el hallazgo de información importante. Atribuyo esto a lo desactualizadas que están las bases de datos de los fondos, y también a la falta de conciencia histórica que tienen algunas instituciones, como él es el caso de nuestra Masonería. La actualización, tecnológica y metodológica, es vital para la investigación. Además, hay que convencer a los poseedores de archivos, institucionales o personales, que estos no tienen ninguna utilidad práctica sino se utilizan para producir conocimiento. 
¿Ahora, cuáles son sus proyectos profesionales?

Tengo el proyecto de grabar la música editada en la Tesis. Hay en Venezuela suficientes músicos profesionales que son masones y muchos de ellos están dispuestos a sumarse a esta iniciativa. También quiero publicar otras obras musicales venezolanas del siglo XIX que he editado. Entre ellas una Sinfonía y un Quinteto, esté último perteneciente al compositor Federico Villena, destacado músico y también masón.

¿Quisiera destacar algún aspecto que no se ha contemplado y que usted consideraría digno de reseñar?

Durante el arqueo de fuentes verifiqué la existencia, en la sección de Libros Raros de la Biblioteca Nacional, de literatura masónica producida y publicada en el país. Hallé un cuento de corte histórico-costumbrista publicado en 1927, cuyo título es iMuera la Masonería. En él se relata un hecho, supuestamente histórico, acaecido en los tiempos de la Independencia (1825). También existe una novela corta, llamada Historia de un vividor, publicada en 1913. El personaje principal de esta novela es, entre otras cosas, el Gran Secretario del Gran Oriente de Venezuela durante las década de 1840. Ambos fueron escritos por connotados masones miembros del Partido Liberal, el cual gobernó a Venezuela durante toda la segunda mitad del siglo XIX. Su lectura es francamente amena y, a pesar de su carácter literario, no dejan de ser reveladores del papel que jugaba la institución masónica en aquellos tiempos.

Otro tesoro que contiene la sección de Libros Raros es una publicación llamada Estudios históricos y simbólicos sobre la franc-masonería, escrito por la "Hermana Susana", seudónimo de Carolina de Silva. Fue publicado en Caracas en 1887, y hasta donde he podido investigar, se trata de la única obra escrita sobre masonería por una mujer latinoamericana en el siglo XIX.

Esta entrevista se efectúo de forma telemática el 06 de Febrero de 2016.

Autores de la entrevista: Ricardo Martínez Esquivel e Yván Pozuelo Andrés, Director y Editor de REHMLAC+.

DOI: http://dx.doi.org/10.15517/rehmlac.v8i1.24278 